\title{
CHOICE BETWEEN NON-EQUITY ENTRY MODES: AN ORGANIZATIONAL CAPABILITY PERSPECTIVE
}

\author{
M. Krishna Erramilli \\ Nanyang Technological University \\ Sanjeev Agarwal \\ Iowa State University \\ Chekitan S. Dev \\ Cornell University
}

ACKNOWLEDGEMENT

The authors thank Jeff Weinstein of the Global Hoteliers Club and Vikram Mujumdar for their assistance in this research, and acknowledge the support of the summer research program of the Cornell School of Hotel Administration. The authors also acknowledge the comments of the three anonymous reviewers who provided valuable guidance. 


\title{
CHOICE BETWEEN NON-EQUITY ENTRY MODES: AN ORGANIZATIONAL CAPABILITY PERSPECTIVE
}

\begin{abstract}
Many studies have examined the choice between different types of equity and non-equity modes; however, none has focused on the choice between different types of non-equity modes that service-firms employ routinely. This study develops a theoretical framework based on the "organizational capability" perspective to explain the choice between two non-equity modes franchising - and management-service contracts. While previous studies are based on the premise that foreign-market entrants choose a modeequity or non-equity-that offers them most control given their particular circumstances, the premise of this study is that foreign entrants choose a non-equity mode that, in addition, offers effective transfer of the firm's capabilities to the host-country venture.
\end{abstract}




\section{INTRODUCTION}

Non-equity modes, defined as modes that do not entail equity investment by a foreign entrant, are becoming increasingly popular among service firms for organizing overseas ventures/operations. Nonequity modes are especially popular among consumer-services firms (such as hotel and restaurant firms) as compared to professional-services firms (such as consulting firms) (Erramilli, 1990). Non-equity modes are essentially contractual modes, such as leasing, licensing, franchising, and management-service contracts (Dunning, 1988).

For many service firms desirous of entering foreign markets, an important question is not how to choose between different equity and non-equity modes but how to choose between different non-equity modes for organizing their operations in the foreign markets. While several previous studies have examined the choice between equity and non-equity modes for manufacturing (e.g., Gatignon and Anderson, 1988; Agarwal, 1994; Tse, Pan, and Au, 1997; Arora and Fosfuri, 2000; Pang and Tse, 2000) as well as service firms (e.g., Agarwal and Ramaswami, 1992; Erramilli and Rao, 1993; FladmoeLindquist and Jacque, 1995; Erramilli, 1996; Contractor and Kundu, 1998a; Contractor and Kundu, 1998b), the extant literature does not offer a theoretically sound-and empirically corroborated-framework for how service firms could choose between different types of non-equity modes. The present study attempts to address this issue in the context of the multinational hotel industry. The reason for choosing this industry is that hotels are renowned for their use of non-equity modes (Contractor and Kundu, 1998b). In the hotel industry, non-equity modes account for $65.4 \%$ of multinational properties worldwide (Contractor and Kundu, 1998b). The two most commonly employed non-equity modes by the hotel industry are franchising and management-service contracts (MSC). Hotel firms typically do not make any equity investment in either of these modes, although some firms may combine non-equity arrangements with equity investments (Dunning, 1988). Although both franchising and MSCs are non-equity modes, there are important differences between them. 
First, in franchising, the foreign entrant (the franchiser) receives royalties from the host-country collaborator (the franchisee) and supply-chain markups. In MSCs, the foreign entrant may receive some combination of royalties, supply-chain markups, management fees, and a share of profits. Second, under the franchising mode, the franchiser typically leases its brand name, and provides marketing support, technical advice and training, to the franchisee. However, the day-to-day involvement of the franchiser in the running of the franchised hotel property in the host country is rather minimal. Although many exceptions abound due to the manner in which franchising contracts are written, the franchiser typically enjoys some strategic control but relatively little operational control in most franchising agreements. In contrast, under MSCs, the foreign entrant not only leases its brand name to a host-country collaborator, but secures a contract to provide extensive onsite technical and management support. Its managers are assigned to the specific hotel property in the host country on deputation to run it on a day-to-day basis. They often enjoy complete de facto strategic and operational control (Contractor and Kundu, 1998b; Dunning, 1988). Such deputation of senior managers on a long-term basis, however, renders a MSC mode more expensive to operate relative to a franchising mode. Third, while franchising is not a pure arm's length market transaction, given the long-term and ongoing nature of the partnership (Shane, 1996), and MSCs are not pure hierarchical arrangements in the classical sense, it may be appropriate to treat franchising as a quasi-market transaction, and MSC as a quasi- internalized transaction (Contractor and Kundu, 1998a; Dunning, 1988; and Fladmoe-Lindquist and Jacque, 1995).

The purpose of this study is to develop a theoretical model to explain the choice between franchising and MSC, and to empirically test the model with data from hotel properties belonging to multinational hotel chains. Traditional international business theories have asserted that firms enter foreign host markets to exploit ownership advantages, presumably developed in their home markets or third-country markets (Dunning, 1988; Agarwal and Ramaswami, 1992). In doing so, they must choose a mode that affords them a higher degree of control. In the context of non-equity modes, entry modes are viewed as conduits for transferring resources and capabilities from a firm to its foreign venture; a role 
recognized by Root (1994), but not emphasized in entry-mode investigations. The theoretical underpinnings for the framework are rooted in the organizational capability (OC) perspective. The OC approach is more appropriate than the traditional international business theories (including transaction cost theory) because the choice between different types of non-equity modes is rooted in the effectiveness of capability transfer, not just concern for control. The paper does not wish to discuss the relative merits and demerits of the OC and transaction cost perspectives, a subject that has received excellent coverage in Kogut and Zander (1993) and Madhok (1997). In line with the general conclusions by these authors that the two perspectives complement each other, we draw on some transaction-cost and internalization arguments in the course of developing the hypotheses.

\section{THEORY AND HYPOTHESIS}

Every firm is thought to be a bundle of resources and capabilities. Resources include all assets, organizational processes, firm attributes, information, and knowledge controlled by a firm that enable it to conceive and implement strategies efficiently and effectively (Barney, 1991). Capabilities refer to a combination of resources that creates higher-order competencies (Madhok, 1997). For example, brand reputation, customer base, and ability to create repeat business, can be viewed as independent resources which, when combined with organizational routines and technology in a judicious manner, could create a capability (say, "customer competence").

As mentioned earlier, the choice between MSC and franchising could be viewed as a choice between a quasi-internal mode and a quasi-market mode. Whereas franchising requires transfer of resources across firm boundaries, MSC involves transfer of capabilities within firm boundaries. Thus an understanding of the factors that affect these transfers would help us understand how firms choose between MSC and franchising. Five factors that affect these external and internal transfers are discussed below. 


\section{Imperfect Imitability}

In line with the OC perspective, the present study defines value of a resource or capability in terms of its contribution to a firm's competitive advantage (Collis and Montgomery, 1995; Madhok, 1997). Obviously, when a firm enters a foreign market, it must transfer the resources and capabilities to its foreign operations. Consequently, a firm should choose an entry mode that can best transfer its resources or capabilities from the home country operations to the host country operations without eroding their value (i.e., without affecting the firm's ability to generate the desired competitive advantage). The question, therefore, is when it does make sense to transfer resources and capabilities via franchising (i.e., a quasi-market mode) and via MSC (i.e., a quasi-internal mode).

In line with the OC perspective, it can be argued that transfer of a resource or capability need not be internalized unless the resource or capability being transferred is imperfectly imitable (Madhok, 1997). When the foreign entrant's resource or capability is imperfectly imitable, the host-country collaborator is unable to absorb or replicate it and perform the needed activities without incurring a substantial loss in value (that is, loss in competitive advantage). Under such circumstances, the entrant undertakes internal transfer to preserve the value of the resource or capability.

Note that the traditional Resource Based View examines the problem of competitors imitating a firm's resources and capabilities and eroding its competitive advantage. The OC approach outlined here is more concerned with collaborators being able to imitate or replicate the foreign entrants' capabilities in order to facilitate across-firm transfer. However, the underlying factors responsible for imperfect imitability are identical regardless of whether one is dealing with competitive or collaborative replication.

What causes imperfect imitability? Barney (1991) suggests that the unique historical paths, causal ambiguities, and complex social interactions that underlie creation of a firm's resources and capabilities render it difficult for other firms to imitate them. To other scholars, it is the tacitness of the resource that makes it difficult to transfer and imitate (Teece, 1998). Hu (1995) suggests that transferring tacit 
knowledge is difficult because it is complex, acquired through experience, and through trial and error, taught and learnt through demonstration, observation, imitation, practice and feedback, and continuously evolving. According to Kogut and Zander (1993), the less codifiable, less teachable, and more complex the knowledge is, the more difficult it is to replicate and transfer across firm boundaries.

From the perspective of the OC approach, imperfect imitability results from embeddedness, i.e., when the capability is deeply embedded within organizational routines and becomes specific to a firm (Madhok, 1997). Lam (1997) explains that embedded knowledge is not owned by any specific individual, but is embedded in complex social interactions and team relationships within an organization. It cannot be systematically coded and it can be transferred only through intimate social interaction. Furthermore, transfer of embedded knowledge requires the use of established routines and organizational processes. For these reasons, the OC perspective suggests that internal modes are more effective than market modes to transfer imperfectly imitable capabilities (Madhok, 1997). Note that internal and market modes are, perhaps, equally effective in transferring capabilities that are imitable. However, the additional costs and risks associated with internal modes may tilt the choice in favor of market modes. Recent studies that have empirically examined the choice between an equity-based internal mode, like wholly-owned subsidiary, and a non-equity based market mode, such as licensing, in the manufacturing sector (Hennart, 1987; Kogut and Zander, 1993; Arora and Fosfuri, 2000), have corroborated the expectation that firms favor internal modes (wholly-owned subsidiaries or joint ventures) when transferring tacit (i.e., imperfectly imitable) capabilities, and market modes (licensing) when transferring codified (i.e., readily imitable) capabilities.

One could extend these arguments to the choice between two non-equity modes. Both MSC and franchising could be equally effective in transferring perfectly imitable capabilities. However, as argued before, MSC is often associated with greater costs and risks than franchising. But it is unclear whether the difference in costs and risks between the two non-equity modes is as great as that between an equity and a non-equity mode. Consequently, one may not observe a clear choice between MSC and franchising when 
the capabilities being transferred are perfectly imitable. The ultimate choice under these circumstances may be contingent on the presence of other factors, such as the availability of managerial staff, development of franchising infrastructure in the host market, and the enforcement of intellectual property laws.

It should be noted that imperfect imitability, as described by the OC framework, is only one approach to sustain a firm's competitive advantage. The OC approach argues that it is the characteristics of these capabilities, principally their embeddedness, that makes them imperfectly imitable. But firms can protect their resources and capabilities through legal means as well, that is, through copyrights, trademarks, patents and licensing. In other words, firms can enjoy a sustainable competitive advantage even though their capabilities are classified as perfectly imitable. Not surprisingly, companies employing franchising show a great deal of concern for the presence and enforcement of intellectual property laws in the host markets. In short, sustainability is a broader concept than "imperfect imitability", as employed by the OC approach.

The transfer of imperfectly imitable capabilities would clearly favor MSC. Any attempted transfer of such capabilities to local franchisees may lead to serious value- erosion and loss of competitive advantage for the foreign entrant, for reasons described earlier. But the influence of these imperfectly imitable capabilities on modal choice depends upon the strength of the competitive advantage generated by them. When they do not generate value for the firm, they may not be transferred to the host market, and are not likely to influence the firm's choice of entry modes. On the other hand, when these capabilities are critical to the firm's competitive advantage, they will dominate modal choice. Thus:

Hypothesis 1: Greater the competitive advantage generated by "imperfectly imitable" capabilities, higher is the firm's probability of choosing a management service contract relative to franchising. 


\section{Availability of Management Capabilities in Host Market}

In addition to the local firm's organizational capacity to replicate the foreign entrant's capabilities, the QC perspective stresses the role of supporting infrastructure within and outside the firm that may facilitate or impede the transfer (Hu, 1995; Madhok, 1997). For example, even if the core resources and capabilities could be transferred through market mechanisms, what happens if the host market lacks good management talent? Franchising becomes a sub-optimal mode to exploit the firm's advantages if host country franchisees lack adequate access to competent managerial staff. Rather than risk destroying the value of its capabilities under such circumstances, the firm may decide to use MSC in an effort to transfer critical managerial capabilities from home country to the host market. Thus:

Hypothesis 2: Lesser the availability of qualified managerial staff in the host market, higher is the firm's probability of choosing a management service contract relative to franchising.

\section{Availability of Investment Partners in Host Market}

For management service contracts to become reality, there must exist qualified and trustworthy partners in the host market with complementary capabilities, that is, partners who can make the necessary capital investments (Dunning, 1988; Contractor and Kundu, 1998b). These complementary capabilities free up the foreign entrant to focus on managing the hotel. Lack of such qualified and trustworthy investment partners impedes establishment of MSCs. Thus:

Hypothesis 3: Greater the availability of qualified and trustworthy investment partners in the host market, higher is the firm's probability of choosing a management service contract relative to franchising. 


\section{Development of Host Country Business Environment}

As mentioned earlier, for effective transfer of resources and capabilities to occur, not only are its characteristics important, but the capabilities of the local collaborator are also important. Cohen and Levinthal (1990) underscore the importance of the "absorptive capacity" of receiving firms. Contractor and Kundu (1998a) argue that, generally speaking, franchising, as a system, is more developed and franchisees, as individual entities, are more capable in more developed countries than in less developed ones. They also note that the use of franchising in developed nations is promoted by the existence and enforcement of intellectual property laws. Based on this reasoning, they find that the propensity to franchise increases (in relation to company-run operations) as the host market becomes more developed. Extending this logic to the present study, it appears that franchising becomes more viable in relation to MSC when the host market business environment is more developed. Thus:

Hypothesis 4: Greater the level of development of the host country business environment, lower is the firm's probability of choosing a management service contract relative to franchising.

\section{Cultural Distance of Host Country}

Traditional entry-mode literature holds that firms minimize the high information costs associated with operating in culturally unfamiliar countries by seeking collaborative modes (Gatignon and Anderson, 1988; Agarwal, 1994). While no apparent relationship between sociocultural distance and modal choice has been found in the hotel sector (Contractor and Kundu, 1998a; Contractor and Kundu, 1998b), empirical evidence in the general service sector (Erramilli and Rao, 1993; Fladmoe-Lindquist and Jacque, 1995) and in the manufacturing sector (Gatignon and Anderson, 1988; Agarwal, 1994), supports the prediction that collaborative modes are preferred in culturally distant markets.

In general, all non-equity modes are collaborative because they necessarily involve a local partner. However, the role of the collaborator can shed some light on the degree and strength of the 
collaboration. Franchising involves a strong local collaborator who essentially manages the entire interface with local labor, suppliers, regulatory authorities, customers and the community. MSCs involve a sleeping or passive collaborator, and the interface with all external entities in the host market is the management company's responsibility. Consequently, while franchising resembles a joint-venture type collaboration, a MSC tends to have characteristics of a sole venture.

One of the OC arguments supports the traditional perspective on cultural distance, although for different reasons. According to this view, organization routines that are effective in the home country may not be so in the host market when high cultural distance exists. This impedes capability transfer within firm boundaries (Madhok, 1997). To prevent value erosion, firms must collaborate with host country entities whose routines are better adapted to the local conditions.

It must be noted that the relationship between cultural distance and ownership is far from certain. As Brouthers and Brouthers (2001) and Shenkar (2001) have noted, the empirical evidence is ambiguous, even contradictory. They cite studies that have found no relationship, positive relationship, as well as, negative relationship between cultural distance and the desire to establish collaborative modes.

Even the OC approach offers a very intriguing counterview. High socio-cultural distance could result in ineffective resource transfer across firm boundaries because of (a) a mismatch in the foreign entrant's and local collaborator's routines and capabilities, and/or (b) the local collaborator's lower absorptive capacity (Contractor and Kundu, 1998a; Madhok, 1997; Lam, 1997). Therefore, when cultural distance is large, the foreign entrant may actually prefer to internalize the transfer to preserve the value of its capabilities (and the resulting competitive advantage). However, given the preponderance of the evidence in favor of the collaborative modes, the following hypothesis is offered:

Hypothesis 5: Larger the cultural distance between home and host countries, lower is the firm's probability of choosing a management service contract relative to franchising. 


\section{Control Variables}

Four firm-specific factors and one market- specific factor are included in the analysis to control for possible extraneous variation: (a) size of the foreign entrant, (b) international experience of the foreign entrant, (c) size of the subsidiary hotel property, (d) reputation of the foreign entrant in the host market, and (e) service-sensitivity of the hotel's target audience. The entry-mode literature predicts that the likelihood of establishing internal, company-run modes is higher for firms that are larger and more experienced, and have strong reputation (to prevent collaborators from free-riding). On the other hand, the likelihood of establishing internal, company-run modes, is lower for foreign entrants that establish larger subsidiaries (Gatignon and Anderson, 1988; Erramilli and Rao, 1993; Contractor and Kundu, 1998a; Contractor and Kundu, 1998b). Also, extraneous variation in modal choice could arise between hotels serving highly service-sensitive markets (in which customers are very particular about the quality of service they receive) and those targeting less service-demanding markets.

\section{Interaction Effects}

Following other entry-mode studies that have underscored the importance of interaction effects (Agarwal and Ramaswami, 1992; Erramilli and Rao, 1993), we propose to include some interaction effects in the model. One of the objectives is to understand how firms make tradeoffs when pulled in opposite directions. The specific interaction effects will be identified subsequently.

\section{METHODOLOGY}

\section{Data Collection and Sample}

A questionnaire was developed and pre-tested on a sample of 30 Hotel General Managers who attended an executive program at Cornell University. The questionnaire was modified based on their 
feedback. The questionnaire was mailed to managers of five hundred and thirty hotels belonging to the Global Hoteliers Club. A reminder was sent two weeks later and a second reminder was sent four weeks later with the copy of the questionnaire. Two hundred and one usable questionnaires were received. The response rate was a respectable 39 percent.

Thirty-eight non-respondents (hotels that did not respond even after the two reminders) were later faxed a short one-page form with some particulars about the background of the hotel and requested to complete the form and fax it back. Eleven hotels responded. Information provided by these hotels was compared with comparable data from the respondents. Also, the background information of the early respondents was compared to that of the late respondents (Armstrong and Overton, 1977). Taking these results together, it was concluded that non-response bias is negligible.

Respondents were asked to indicate the description that best captured the foreign entrant's involvement in their property. Based on the responses, entry modes other than pure franchising and pure management contracts were removed from the analysis, resulting in a sample of 139 observations. Table 1 summarizes the salient characteristics of the analysis sample. The vast majority of the respondents are General Managers of the hotels surveyed (which helps improve the quality of data). Also, there are 46 countries represented in the sample, assuring the representation of a diversity of environments.

\section{Variables}

The Appendix lists the variables and their measures used in the study. The primary dependent variable, $Y 1, M O D E$ is assigned a value of 0 for franchising and 1 for MSC. Franchising accounted for $25.2 \%$ of the observations. The second dependent variable Y2, INIMIT, is used to identify imperfectly inimitable capabilities.

Variables Needed to Test H1: To test this hypothesis, one needs to identify the "imperfectly imitable" capabilities that drive a firm's competitive advantage. As defined by the OC approach, 
capabilities are combinations of resources and skills. Therefore, a list of 22 resources was drawn from a variety of sources: Chandler \& Hanks' (1994) list of resources, the researchers' industry knowledge and interactions with hotel managers. Survey respondents were asked to rate the extent to which the foreign entrant enjoyed a competitive advantage in each of the 22 resources $(1=$ No advantage, $5=$ Great advantage). Their responses were factor analyzed (using the principal components method with varimax rotation) resulting in five factors. This led to the identification of five capabilities for the foreign entrant. Organizational Competence (X1, ORGCOMP) embraces a range of organizational skills and resources that enable the hotel to compete better, such as corporate culture, empowerment, operating policies and procedures, and reservation systems. Quality Competence $\{X 2, Q U A L C O M P\}$ includes skills and resources needed to offer high quality service and ensure customer satisfaction. Customer Competence $\{X 3$, CUSTCOMP $\}$ encompasses a variety of skills that help the hotel to create brand reputation, establish a customer base, and build customer loyalty. Entry Competence $\{X 4, E N T R C O M P\}$ taps the hotel's abilities to find good locations and to time its entry into a certain market. Physical Competence (X5, PHYSCOMP) captures the hotel's skills to design and build physical facilities that are of desirable quality, comfort and ambience.

We defined imperfectly imitable capabilities as those that contribute significantly to the "inimitability" of a hotel's overall competitive advantage. First, we created a variable called INIMIT $\{Y 2\}$, which measures the perceived degree to which other firms can copy or imitate the foreign entrant's overall competitive advantage in the host market. This is not specific to individual capabilities, but represents a global measure of inimitability of the foreign entrant's competitive advantage, as perceived by the respondent. Although this variable measures imitation by competitors, it can be equally effective to explain imitation by host-country collaborators, because the underlying causes for imperfect imitability are identical, as argued above.

We regressed the five capabilities, described above, against INIMIT, and compared their standardized beta coefficients. The results are summarized in Table 2. The larger the coefficient, the more 
the specific competence contributes to the inimitability of the hotel's competitive advantage. Clearly, Organizational Competence (ORGCOMP) and Quality Competence (QUALCOMP) are not only statistically significant, but are also the largest contributors to INIMIT. In other words, the greater the competitive advantage generated from ORGCOMP and QUALCOMP, the more inimitable is the hotel's overall competitive advantage. On the other hand, Customer Competence (CUSTCOMP), Entry Competence (ENTRCOMP), Physical Competence (PHYSCOMP) are not statistically significant, suggesting that they do not contribute to the inimitability of the hotel's competitive advantage. Based on this evidence, we conclude that ORGCOMP and QUALCOMP represent capabilities that are imperfectly imitable.

To further test the validity of the above results, respondents were asked to rate each of the underlying 22 resources in terms of the difficulty of transferring them from the foreign entrant's operations to the local operation through franchising $(1=$ very easy to transfer, $5=$ very difficult to transfer). Using this data, the mean difficulty of transfer was calculated for the five capabilities. Results reported in Table 2, generally support the expectation that ENTRCOMP and PHYSCOMP appear to be the easiest to transfer, while QUALCOMP, CUSTCOMP and ORGCOMP are more difficult to transfer via arms-length modes. This evidence supports the general thesis in this study that imperfectly imitable capabilities are more difficult to transfer via market mechanisms than the imitable ones.

Variables Needed to Test H2-H5: The Appendix provides a detailed description of the other variables used in the study. Where appropriate, the reliability coefficients are also reported. MGMTA VAIL (X6 \} measures the availability of managerial staff in the host market, whereas PRTNRA VAIL (X7\} indicates the availability of investment partners in the host country. BUSENV $\{\mathrm{XB}\}$ represents the level of development of the host-country market, and CULTDIST $\{$ X9 $\}$ captures the cultural differences existing between home and host countries, as perceived by the respondents. In order to examine the face validity of these measures, Table 3 compares means of these four variables for developed (OECD countries) and developing host countries. As expected, the means for MGMT AVAIL, PRTNRAVAIL, and 
BUSENV are larger for developed countries. The mean for CULDIST is lower for developed countries, since most of the hotel firms (foreign entrants) are from developed countries. This evidence provides considerable face validity for the measures.

Control Variables: FIRMSIZE $\{\mathrm{X} 10\}$ measures the size of the hotel firm (i.e., the foreign entrant) in terms of the number of hotels in the chain worldwide, whereas FIRMEXP $\{\mathrm{X} 11\}$ captures the firm's international experience in years. The size of the hotel property in the host market is captured by HTLSIZE $\{\mathrm{X} 12\}$, and its reputation is represented by HTLREPUTE $\{\mathrm{X} 13\}$. Finally, the degree to which customers in the host market are sensitive to high-quality service, is measured by SRVCSENS $\{\mathrm{X} 14\}$.

Interaction Effects: Four interaction terms are included in the model to understand how firms make modal choices, particularly when pulled in opposite directions. First, the ORGCOMPXBUSENV interaction will answer the question "will the firm serving developed markets prefer franchising (as posited in H4), even when its capabilities are imperfectly imitable (H1)?" Second, the HTLREPUTExPHYSCOMP interaction will address the question, "Given the fact that imitable capabilities like PHYSCOMP may not, by themselves, discriminate well between non-equity modes, will combination with a contingent factor, like hotel reputation, do so?" Third, an answer to the question, "will the firm's preference for MSC when transferring Quality Competence become stronger in servicesensitive markets?" will be provided by the QUALCOMPxSRVCSENS interaction. Finally, the QUALCOMPxHTLSIZE intraction term is included to gain insights into the issue of transferring and managing capabilities to produce high-quality customer service for larger hotel properties. Extending the arguments made by some scholars (e.g., Shane, 1996), will the resultant problem of monitoring and controlling employees represent such a management challenge that the firm would sacrifice value and switch to franchising when host-country hotel properties are large? 


\section{ANALYSIS AND RESULTS}

The independent variables are standardized to mean zero and standard deviation one. The correlation matrix (not reported here due to space constraints) revealed that most of the correlations among the 14 variables are relatively small. Further, an examination of the variance-inflation factors (VIF) (which were calculated for all of the independent variables) reveals that most of these are close to 1. The largest VIF value is 2.15, which is well below the cut-off of 10 recommended by Neter, Wasserman, and Kutner (1985). The evidence suggests that multicollinearity is, perhaps, not a serious problem with this data.

Table 4 summarizes the results for two logistic regression models explaining the choice between franchising (MODE $=0)$ and MSC (MODE = 1). Model 1 reports the results for the main effects only, whereas Model 2 includes interaction effects as well. The hypotheses are evaluated based on Model 1 results, since the predictions involve main effects.

Hypotheses Testing: Model 1 enjoys good fit $(\mathrm{x} 2=31.25, \mathrm{p}=0.005)$. Note that a positive sign on a coefficient suggests that the likelihood of choosing MSC increases relative to franchising, and a negative sign implies that it decreases, as the value of the associated predictor increases.

As described earlier, Organizational Competence (X1) and Quality Competence (X2) have been identified as the imperfectly imitable capabilities. In Table 4, both coefficients are statistically significant with positive signs suggesting that the likelihood of MSC increases as the contribution to the firm's competitive advantage from these two capabilities increases. Incidentally, the three other capabilities, Customer Competence (X3), Entry Competence (X4) and Physical Competence (X5), which are imitable capabilities, do not have any impact on the choice between franchising and MSC. In combination, the results provide powerful support for $\mathrm{H} 1$. The statistically significant negative and positive coefficients for MGMTVAIL (X6) and PRTNRAVAIL (X7\}, respectively, suggest that the likelihood of choosing MSC relative to franchising increases as managerial talent becomes scarcer and investment collaborators 
become more abundant in the host country. These results support hypotheses H2 and H3, respectively. BUSENV (XB) has a significant negative sign, suggesting that franchising is preferred as the level of development of the host-country business environment is greater, as predicted by H4. CULTDIST (X9) is not a significant predictor, however, and so HS has to be rejected.

Interaction Effects: The Model 2 results reveal that the four interaction terms are highly significant. Although interaction effects can be interpreted in more than one way, the following interpretations are offered in view of the questions raised earlier. First, although foreign entrants seem to generally prefer franchising as the host business environment becomes more developed, they switch to MSC when Organizational Competence, an imperfectly imitable capability, makes an increasingly greater contribution to their competitive advantage. Second, while Physical Competence, by itself, may not influence the selection of the franchising mode (because it is imitable), it can become a powerful predictor in conjunction with strong firm reputation. Third, the firm's proclivity to employ MSC with rising importance of the Quality Competence becomes stronger in larger hotels. Finally, the influence of Quality Competence on modal choice becomes stronger when the hotel's market tends to be servicesensitive.

Model 2 results also show that CULTDIST and CUSTCOMP, which were both insignificant in the main-effects only model, are significant with positive signs in the model including interactions. Evidently, the propensity for MSC is higher when cultural distance between home and host countries is higher. The propensity for MSC is also higher when the advantage generated by customer competence is higher.

\section{DISCUSSION AND CONCLUSION}

While a significant amount of research has been devoted to understanding the choice between equity and non-equity modes, relatively little is known about how firms choose between different types of 
non-equity modes. The paper attempts to address this gap in the literature. It describes a study of modal choices in 139 hotels based in 46 different countries. It develops several hypotheses, based largely on the Organizational Capability (OC) perspective, to explain the hotel firm's choice between a franchising and management service contract. Four out of the five hypotheses were strongly supported.

First, the significant, positively signed intercept term in both models (Table 4), supports the often-observed phenomenon that firms intrinsically prefer the internal, high-control mode (Gatignon and Anderson, 1988; Erramilli and Rao, 1993). This is an interesting piece of evidence that fails to support the transaction-cost contention that market modes are the default modal choice.

Second, the results provide strong support for the DC-based proposition that imperfectly imitable capabilities, like Organizational Competence and Quality Competence, cannot be transferred effectively through market modes (Madhok, 1997). Imperfect imitability not only protects the firm from its competitors, it thwarts efforts to transfer the needed capabilities to associates and collaborators in the host market, "forcing" it to adopt internal modes. This finding is generally consistent with studies demonstrating that difficult-to-codify tacit know-how is transferred internally (e.g., Kogut and Zander, 1993; Arora and Fosfuri, 2000).

On the other hand, the transfer of easy-to-replicate capabilities (e.g., Physical Competence) does not appear to directly influence non-equity modal choice since they can be transferred equally effectively by the internal non-equity mode (MSC) as well as the market non-equity mode (franchising). This is at variance with studies contrasting an internal equity mode (wholly-owned subsidiary) with a market nonequity mode (licensing), where the latter mode is clearly preferred when codified know-how is transferred (e.g., Kogut and Zander, 1993; Arora and Fosfuri, 2000). The finding, perhaps, suggests that the difference in transfer costs between non-equity modes is not large enough to produce unambiguous choices. However, the significant interaction between PHYSCOMP and HTLREPUTE sheds some light on the conditions under which clear choices could result when transferring imitable capabilities. While 
the transfer of Physical Competence, by itself, does not clearly favor any one mode, it unambiguously favors franchising when combined with a strong brand.

The QUALCOMP and HTLSIZE interaction is interesting in that it underscores the importance of scale effects on modal choice. Other scholars have observed that firms shift to collaborative modes when the scale of operation grows larger, either to reduce risks (Gatignon and Anderson, 1988) or to minimize management problems (Shane, 1996). Our result suggests that as Quality Competence (imperfectly imitable capability) becomes more important as a source of competitive advantage, the firm's desire for internal modes becomes even stronger as the size of the planned hotel property is larger. Evidently, the know-how needed to offer quality service becomes more complex (and even less imitable) as the hotel property expands in size, thus making MSC all the more necessary to transfer key capabilities to the host market.

The interaction between QUALCOMP and SRVCSENS highlights the interplay between internal capabilities and external market requirements, a noted strength of the resource-based and capabilitybased approaches (Collis and Montgomery, 1995). As the hotel's customers become more serviceconscious and demand greater service, hotels stronger in quality competence become even more committed to internal modes like MSC.

The results also corroborate the OC contention that firms cannot exploit their advantages without the benefit of a whole range of internal and external support capabilities (Madhok, 1997; Hu, 1995). Franchising becomes more attractive as the availability of managerial staff (MGMT AVAIL) increases in the host market. When this external capability is scarce, firms have to make up for the shortfall through internal transfers (i.e., via MSCs). Similarly, the finding for PRTNRA VAIL implies that the MSC option becomes increasingly attractive with greater availability of reliable investment partners in the host market.

In addition to the availability of certain resources in the environment, the effectiveness of these resources is also critical. The result for BUSENV suggests that, as potential collaborators (e.g., 
franchisees) with high levels of competence and "absorptive capacity" become more abundant in the host market, entrant firms become more comfortable with franchising. This is generally consistent with findings reported by other researchers (Contractor and Kundu, 1998a; Fladmoe-Lindquist and Jacque, 1995). On the other hand, the interaction between ORGCOMP and BUSENV also emphasizes the fact that firms will be primarily driven by the transfer characteristics of their-advantage generating capabilities when making modal decisions. When these capabilities are imperfectly imitable, they not only shun franchising, but also become stronger advocates for MSC in developed markets (perhaps, to gain a bigger share of the revenue streams). In other words, while external support capabilities are important, modal choice appears to be primarily driven by internal capability considerations.

The non-significant result for CULTDIST (perceived cultural distance between home and host countries) in Model 1 is in line with the results reported for hotels in Contractor and Kundu (1998a and 1998b). However, there may well be some confounding influences suppressing the relationship. When these are apparently removed in Model 2 (most likely due to the strong interaction terms), the effect becomes significant and positively signed. Apparently, the preference for internal modes, like MSC, increases (relative to collaborative modes) as cultural distance becomes larger. Obviously, this contradicts findings on cultural distance in traditional entry-mode studies (e.g., Gatignon and Anderson, 1988; Agarwal, 1994), but is quite consistent with one of the OC perspective's arguments that internal modes may be more effective in culturally distant markets because differences in partner capabilities and routines make transfers across firm boundaries ineffective (Madhok, 1997).

None of the control variables apparently has any direct impact on modal choice. It is worth noting that firm characteristics, like size of the foreign entrant, size of the host country property, the entrant's international experience and brand reputation, all of which have been found to significantly influence choice between different types of equity modes and between equity and non-equity modes (e.g., Gatignon and Anderson, 1988; Agarwal and Ramaswami, 1992; Contractor and Kundu, 1998b), apparently have no 
direct influence on the choice between non-equity modes. Firms are seemingly indifferent to costs and risks associated with the two non-equity modes.

The present study is perhaps the first empirical study exclusively focused on the choice between different non-equity modes. It is also one of a few recent attempts to examine a mode's effectiveness in transferring capabilities as the basis for explaining modal choice. The results help provide support and corroboration to the emerging OC framework. Madhok (1997) identifies the lack of measurement for key constructs, like imperfect imitability, as a stumbling block for development of the OC perspective. The procedure outlined here to identify capabilities characterized by imperfect imitability is a useful step forward in alleviating this problem.

Although the study focuses on the hotel industry, its key findings are generalizable to non-equity modal choices in other service industries and in manufacturing firms. In a more general sense, they are relevant to any modal choice, equity or non-equity, as long as one is able to frame the choice as a contrast between internal and market-based modes. The ideas that capabilities generating competitive advantage influence modal choice, that imperfectly imitable capabilities push firms towards internal modes, and that the availability of a support infrastructure is critical to the type of mode chosen, are all universally applicable to any DC-based explanation of entry-mode choice.

Future research could aim to further improve the measures discussed in this study. Also, a wider range of non-equity modal choices could enrich the analysis. Replications in other industry settings would obviously serve to test the generalizability of these findings. 


\section{REFERENCES}

Agarwal, Sanjeev. 1994. Socio-cultural Distance and the Choice of Joint Ventures: A Contingency

Perspective. Journal of International Marketing, 2(2): 63-80.

\& Sridhar N. Ramaswami. 1992. Choice of Foreign Market Entry Mode: Impact of Ownership, Location, and Internalization Factors. Journal of International Business Studies, 23(1): 1-27.

Anderson, Erin \& Hubert Gatignon. 1986. Modes of Foreign Entry: A Transaction Cost Analysis and Propositions. Journal of International Business Studies, 17 (Fall): 1-26.

Armstrong, Scott J. \& Terry S. Overton. 1977. Estimating Non-Response in Mailed Surveys. Journal of Marketing Research, 14(August): 396-402.

Arora, Ashish \& Andrea Fosfuri. 2000. Wholly-owned Subsidiary Versus Technology Licensing in the Worldwide Chemical Industry. Journal of International Business Studies, 31(4): 555-572.

Barney, Jay. 1991. Firm Resources and Sustained Competitive Advantage. Journal of Management, 17(March): 99-120.

Brouthers, Keith D. \& Lance Eliot Brouthers. 2001. Explaining the National Cultural Distance Paradox. Journal of International Business Studies, 32(1): 177-189.

Chandler, Gaylen N. \& Steven H. Hanks. 1994. Market Attractiveness, Resource- based Capabilities, Venture Strategies, and Venture Performance. Journal of Business Venturing, 9(July): 331-349.

Chang, Sea Jin. 1995. International Expansion Strategy of Japanese Firms: Capability Building Through Sequential Entry. Academy of Management Journal, 38(2): 383-407.

Cohen Wesley M. \& Daniel A. Levinthal. 1990. Absorptive Capacity: A New Perspective on Learning and Innovation. Administrative Science Quarterly, 35: 128-152. 
Collis, David J. \& Cynthia A. Montgomery. 1995. Competing on Resources: Strategy in the 1990s. Harvard Business Review, (July-August): 118-128. Contractor, Farok J. \& Sumit K. Kundu. 1998a. Franchising Versus Company-run Operations: Modal Choice in the Global Hotel Sector," Journal of International Marketing, 6(2): 28-53.

_ \& _ . 1998b. Modal Choice in a World of Alliances: Analyzing Organizational Forms in the International Hotel Sector. Journal of International Business Studies, 29(2): 325-358.

Dunning, John H. 1988. Explaining International Production. London: Unwin Hyman. Erramilli, M. Krishna. 1990. Entry Mode Choice in Service Industries. International Marketing Review, 7(5): 50-62. . 1996. Nationality and Subsidiary Ownership Patterns in Multinational Corporations. Journal of International Business Studies, 27(2): 225-248.

__ \& C.P. Rao. 1993. Service Firms' International Entry Mode-choice: A Modified Transaction-Cost Analysis Approach. Journal of Marketing, 57(July): 19-38.

Fladmoe-Lindquist, Karin \& Laurent L. Jacque. 1995. Control Modes in International Service Operations: The Propensity to Franchise. Management Science, 41(7): 1238-49.

Gatignon, Hubert \& Erin Anderson. 1988. The Multinational Corporations' Degree of Control over Foreign Subsidiaries: An Empirical Test of a Transaction Cost Explanation. Journal of Law, Economics, and Organization, 4(2): 305-336.

Gomes-Casseres, Benjamin. 1989. Ownership Structures of Foreign Subsidiaries. Journal of Economic Behavior and Organization, 11: 1-25.

Hennart, Jean-Francois. 1987. A Transaction Costs Theory of Equity Joint Ventures. Strategic Management Journal. 9: 361-374.

Hu, Yao-Su. 1995. The International Transferability of the Firm's Advantages. California Management Review, 37(4): 73-88. 
Kogut, Bruce \& Udo Zander. 1993. Knowledge of the Firm and the Evolutionary Theory of the Multinational Corporation. Journal of International Business Studies, 24(4): 625-646.

Lam, Alice. 1997. Embedded Firms, Embedded Knowledge: Problems of Collaboration and Knowledge Transfer in Global Cooperative Ventures. Organization Studies, 18(6): 973-996.

Madhok, Anoop. 1997. Cost, Value and Foreign Market Entry Mode: The Transaction and the Firm. Strategic Management Journal. 18: 39-61.

Neter, John, William Wasserman, \& Michael H. Kutner. 1985. Applied Linear Statistical Models:

Regression, Analysis of Variance, and Experimental Designs, 2nd Edition. Homewood: Richard D. Irwin, Inc.

Pan, Yigang \& David Tse. 2000. The Hierarchical Model of Market Entry Modes. Journal of International Business Studies, 31(4): 535-554.

Root, Franklin R. 1994. Entry Strategies For International Markets. New York: Lexington Books.

Shane, Scott A. 1996. Hybrid Organizational Arrangements and Their Implications for Firm Growth and Survival: A Study of New Franchisers. Academy of Management Journal, 39(1): 216-

234.

Shenkar, Oded. 2001. Cultural Distance Revisited: Towards a More Rigorous Conceptualization and Measurement of Cultural Differences. Journal of International Business Studies, 32(3):

519-535.

Teece, David J. 1998. Capturing Value from Knowledge Assets: The New Economy, Markets for KnowHow, and Intangible Assets. California Management Review. 40(3): 55-79.

Tse, David K., Yigang Pan, \& Kevin Y. Au. 1997. How MNCs Choose Entry Modes and Form Alliances: The China Experience. Journal of International Business Studies, 28(4): 779-805. 
Table 1. Salient characteristics of hotels in sample for analysis $(\mathrm{n}=139)$.

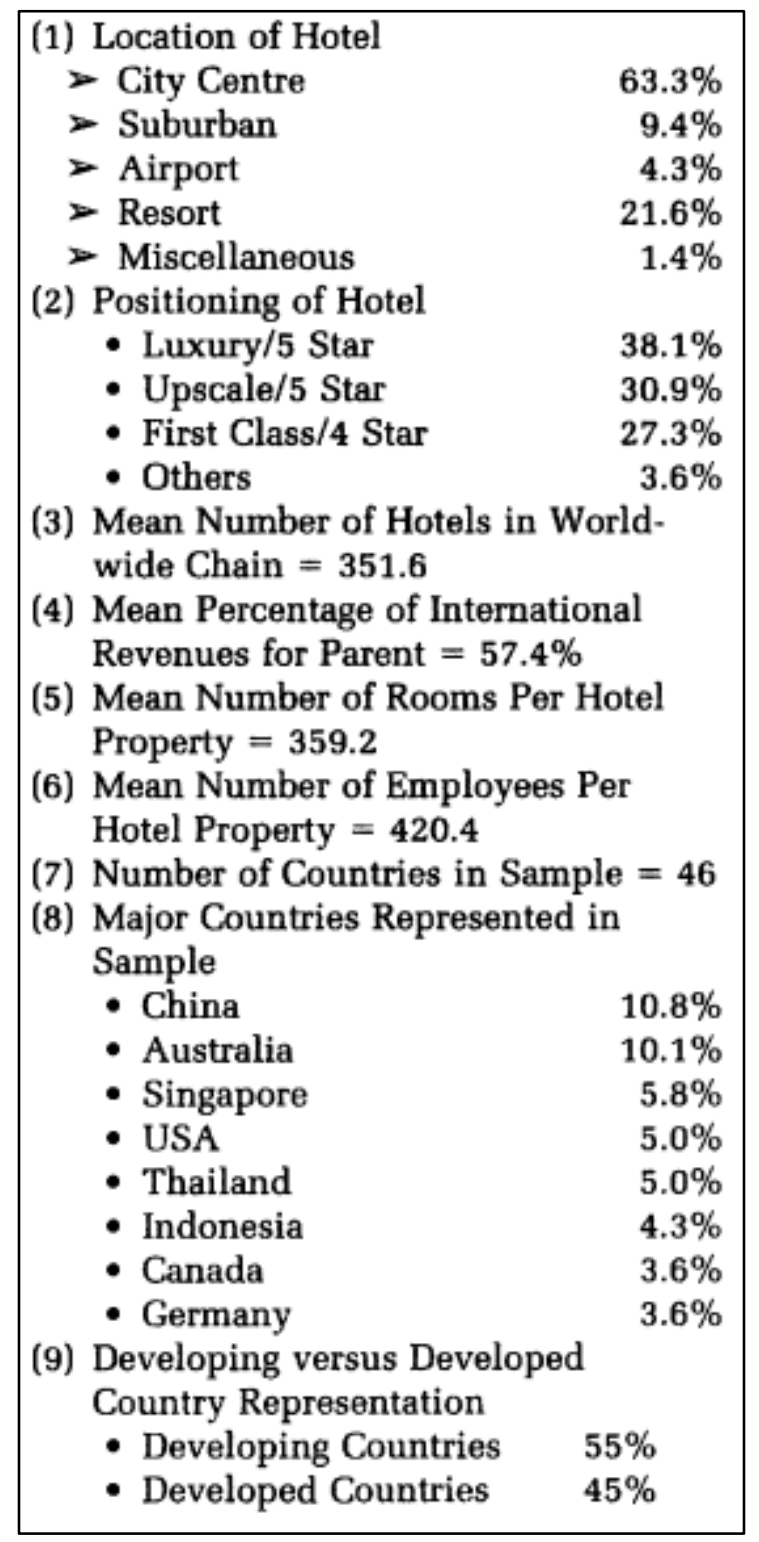


Table 2. Capabilities and their characteristics $(\mathrm{N}=139)$

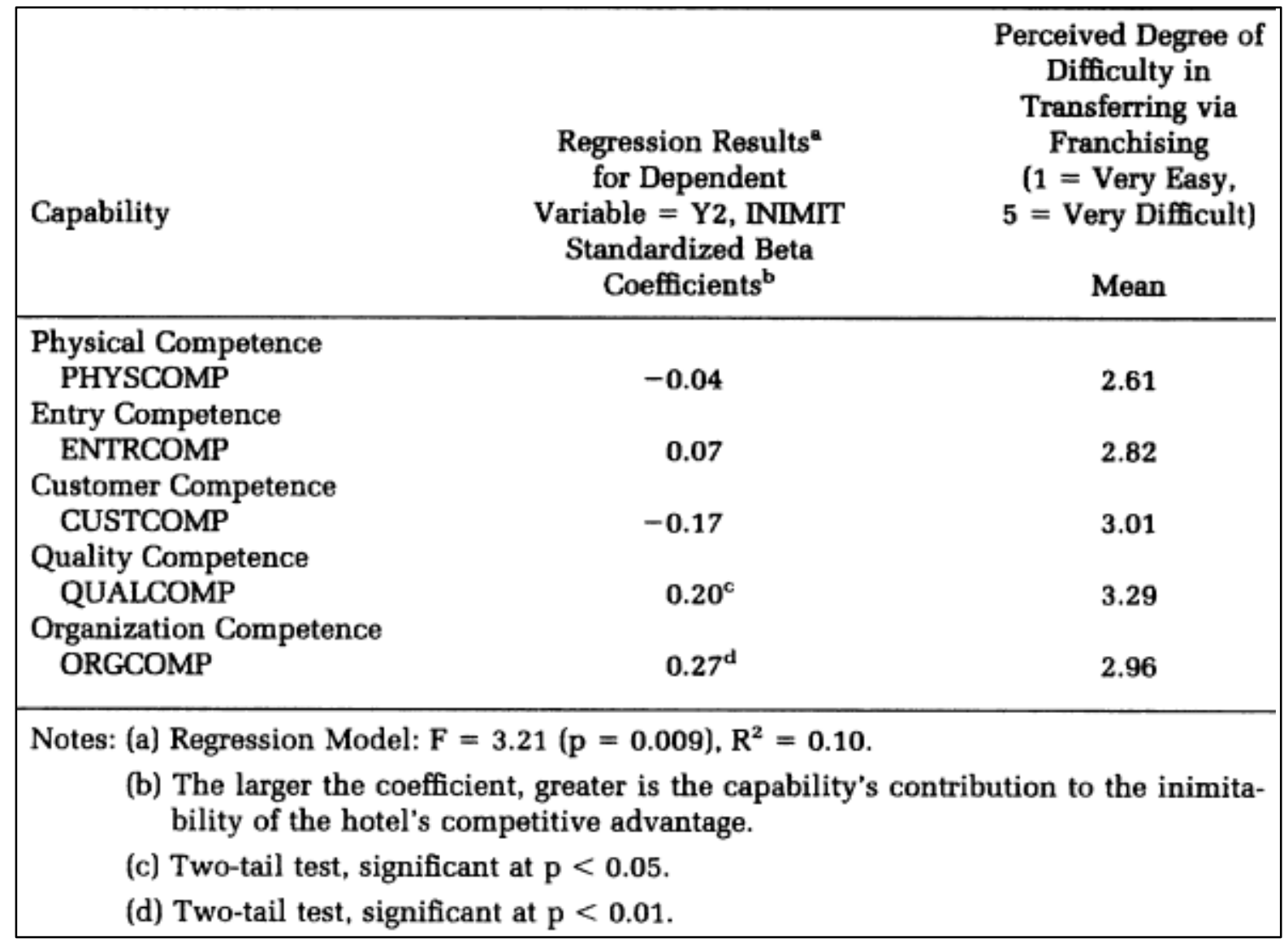


Table 3. Comparison of some research variables: Developed vs. developing countries $(\mathrm{N}=139)$.

\begin{tabular}{|c|c|c|c|}
\hline Research Variable & $\begin{array}{c}\text { Developed Countries } \\
\text { (OECD Countries) } \\
(\mathrm{N}=66) \\
\text { Mean Values }\end{array}$ & $\begin{array}{l}\text { Developing Countries } \\
\text { (All other Countries) } \\
(\mathrm{N}=73) \\
\text { Mean Values }\end{array}$ & $\begin{array}{l}\text { F Test for } \\
\text { Difference } \\
\text { in Means }\end{array}$ \\
\hline Availability of Management Staff & & & 24.9 \\
\hline MGMTAVAIL & 3.03 & 2.18 & $(p=0.000)$ \\
\hline Availability of Partners & & & 3.6 \\
\hline PRTNRAVAIl & 2.85 & 2.53 & $(p=0.067)$ \\
\hline Development of Business & & & 87.9 \\
\hline Environment BUSENV & 4.23 & 3.03 & $(p=0.000)$ \\
\hline Cultural Distance CULTDIFF & & & 14.2 \\
\hline 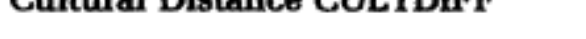 & 3.32 & 4.08 & $(\mathrm{p}=0.000)$ \\
\hline
\end{tabular}


Table 4. Logistic regression results.

\begin{tabular}{|c|c|c|c|}
\hline Dependent Variable: Y1, MODB (0 = Franchising, 1 = & Ganagement & ervice Co & tract) \\
\hline Variable & $\begin{array}{l}\text { Reference } \\
\text { Hypothesis }\end{array}$ & Model 1 & Model 2 \\
\hline Intercept & & $1.503^{d}$ & $2.069^{d}$ \\
\hline Main Effects & & & \\
\hline Organizational Competence (X1, ORGCOMP) & H1 & $0.593^{c}$ & $0.633^{\mathrm{b}}$ \\
\hline Quality Competence (X2, QUALCOMP) & H1 & $0.417^{\circ}$ & $0.923^{b}$ \\
\hline Customer Competence (X3, CUSTCOMP) & H1 & 0.269 & $0.604^{b}$ \\
\hline Entry Competence (X4, ENTRCOMP) & H1 & -0.227 & 0.037 \\
\hline Physical Competence (X5, PHYSCOMP) & H1 & -0.216 & -0.408 \\
\hline Availability of Managers (X6, MGMTAVAIL) & H2 & $-0.531^{b}$ & $-0.625^{b}$ \\
\hline Availability of Partners (X7, PRTNRAVAIL) & H3 & $0.364^{a}$ & $0.797^{c}$ \\
\hline Development of Business Env. (X8, BUSENV) & H4 & $-0.578^{b}$ & -0.308 \\
\hline Cultural Distance (X9, CULTDIST) & H5 & 0.222 & $0.508^{a}$ \\
\hline Control Variables & & & \\
\hline Size of Foreign Entrant (X10, FIRMSIZE) & & 0.325 & $0.631^{\mathrm{a}}$ \\
\hline Intl. Experience of Foreign Entrant (X11, FIRMEXP) & & 0.065 & 0.279 \\
\hline Hotel Size (X12, HTLSIZE) & & 0.137 & $0.815^{c}$ \\
\hline Hotel Reputation (X13, HTLREPUTE) & & 0.134 & -0.308 \\
\hline Service Sensitivity of Market (X14, SERVCSENS) & & -0.347 & -0.357 \\
\hline Interaction Effects & & & \\
\hline ORGCOMP $\times$ BUSENV & & & $0.653^{c}$ \\
\hline PHYSCOMP $\times$ HTLREPUTE & & & $-0.896^{d}$ \\
\hline QUALCOMP $\times$ HTLSIZE & & & $2.200^{\mathrm{d}}$ \\
\hline QUALCOMP $\times$ SRVCSENS & & & $1.270^{\mathrm{d}}$ \\
\hline MODEL STATISTICS & & & \\
\hline $\mathbf{N}$ & & 139 & 139 \\
\hline Model Chi-square & & 31.25 & 58.4 \\
\hline Probability & & .005 & .000 \\
\hline Classification Rate & & $78.4 \%$ & $85.6 \%$ \\
\hline
\end{tabular}




\section{APPENDIX}

\section{Variables Used in the Study}

Y1 Non-Equity Entry Mode (MODE)

Takes value of $\mathrm{O}$ for franchising and 1 for management service contracts

Y2 INIMITABILITY of Competitive Advantage (INIMIT) $\mathrm{a}=0.76$

6-item scale based on following question: Indicate the degree to which you agree/ disagree with the following statements concerning your hotel's competitive advantage in this market. $(1=$ Strongly Disagree, 5 = Strongly Agree).

(a) It is difficult for our competitors to imitate us

(b) Our services are unique and nobody but our company can offer them

(c) It took us years to build our brand reputation-nobody can easily copy it

(d) Our advantages are embodied in the company and not in individuals-nobody can copy us by stealing our employees away from us

(e) We pre-empt our competitors by building our properties in prime locations.

(f) Nobody can copy our corporate routines, processes and culture

X1 Organizational Competence (ORGCOMP) a $=0.87$

6-item scale based on following question: Indicate the degree to which your parent company has competitive advantage in the following areas ( 1 = No Advantage, $5=$ Great Advantage).

(a) Company culture

(b) Employee empowerment

(c) Information technology system 
(d) Operating policies and procedures

(e) Quality of reservation system

(f) Establishing a chain operation

X2 Quality Competence (QUALCOMP) a $=0.92$

6-item scale based on following question: Indicate the degree to which your parent company has competitive advantage in the following areas ( $1=$ No Advantage, $5=$ Great Advantage $)$.

(a) Quality of guest-contact staff

(b) Quality of managerial staff

(c) Ensuring service quality

(d) Ensuring customer satisfaction

(e) Teamwork among employees

(f) Providing appropriate services

X3 Customer Competence (CUSTCOMP) a $=0.83$

3-item scale based on following question: Indicate the degree to which your parent company has competitive advantage in the following areas ( $1=$ No Advantage, $5=$ Great Advantage).

(a) Creating brand reputation

(b) Creating customer base

(c) Creating repeat business

X4 Entry Competence (ENTRCOMP) $\mathrm{a}=0.77$ 
2-item scale based on following question: Indicate the degree to which your parent company has competitive advantage in the following areas ( $1=$ No Advantage, $5=$ Great Advantage $)$.

(a) Finding good locations

(b) Knowing the right time to enter

X5 Physical Competence (PHYSCOMP) $\mathrm{a}=0.93$

4-item scale based on following question: Indicate the degree to which your parent company has competitive advantage in the following areas ( $1=$ No Advantage, $5=$ Great Advantage $)$.

(a) Decor/design of physical properties

(b) Ambience/atmosphere of properties

(c) Comfort of physical facilities

(d) Quality of physical facilities

X6 Availability of Managerial Staff in Host Country (MGT AVAIL)

1-item scale based on responses to following statement measured as ( 1 = Very Low, 5 = Very High)

(a) Availability of qualified managerial staff in the host country

X7 Availability of Investment Partners in Host Country (PRTNA VAIL) a $=0.82$

2-item scale based on responses to following statements measured as $(1=$ Very Low, $5=$ Very High)

(a) Availability of qualified local investment partners to parent company

(b) Availability of trustworthy local investment partners to parent company

X8 Attractiveness of Host Country Business Environment (BUSENV) a $=0.81$ 
3-item scale asking respondent to rate the business conditions in the host-country on 5-point scale $(1$ = Very Poor, 5 = Very Good $)$

(a) Political stability

(b) General business conditions

(c) Quality of infrastructure

X9 Cultural Distance Between Host \& Home Countries (CUL TDIST)

1-item scale based on responses to following statement measured as ( 1 = Very Small, 5 = Very Large).

(a) Differences in culture between this country and the parent's home country

X10 Size of the foreign entrant (FIRMSIZE)

Number of Hotels Worldwide in Chain. (Actual number reported by respondents).

X 11 International Experience of the Foreign Entrant (FIRMEXP)

No. of Years Engaged in International Operations. (Actual number reported by respondents).

X12 Size of Subsidiary Hotel (HTLSIZE)

Number of Rooms in the Subsidiary Hotel in the Host Market. (Actual number reported by respondents).

X13 Reputation of Hotel's Brand in Host Country (HTLREPUTE)

1-item scale asking respondent to rate the reputation of the hotel's brand in the host country on 5-point scale (1 = Very Poor, 5 = Very Good $)$

X14 Service Sensitivity of Hotel's Customers (SRVCSENS) a $=0.71$ 
3-item scale asking respondent whether he/she agrees with the following statements on 5-point scale $(1$ = Strongly Disagree, 5 = Strongly Agree $)$

(a) Our customers belong to a very exclusive class whose needs are unique

(b) Our customers are very particular about the service they receive

(c) We would not succeed in this market without providing excellent service 